\title{
A Study of Knowledge, Awareness, Practice and Recommendations Among Hong Kong Construction Workers on Using Personal Respiratory Protective Equipment at Risk
}

\author{
V. W. Y. Tam ${ }^{1, *}$ and I. W. H. Fung ${ }^{2}$ \\ ${ }^{1}$ Corresponding author, Griffith School of Engineering, Griffith University, PMB 50 Gold Coast Mail Centre, QLD \\ 9726, Australia and ${ }^{2}$ Department of Building and Construction, City University of Hong Kong
}

\begin{abstract}
Pneumoconiosis is considered as one of the hazardous chronic health diseases in the Hong Kong construction industry. Most frontline workers lack proper education and their health and safety awareness is relatively low. Therefore, management of an organization plays a momentous role to implement the control of hazards within organizations and to incorporate health and safety into their operations. Personal protective equipment is designed, only after all health and safety measures, to remove and to control health and safety hazards. In the case of respiratory hazards, the hazard at source is impossible to entirely eliminate. Thus, wearing the personal respiratory protective equipment against the health and safety illnesses becomes critical. This paper examines awareness and attitude in using the personal respiratory protective equipment in the Hong Kong construction industry. Questionnaire survey and structured interviews are conducted. From the survey results, it is found that awareness and understanding of the health and safety hazards, is insufficient. Moreover, workers are not familiar with the risks of the equipment fitting, and health and safety. Health and safety awareness can influence health and safety attitude and behaviour. The low awareness of health and safety would make worker more vulnerable to illness. Recommendations to improve health and safety awareness and understanding of health and safety diseases are also given in this study.
\end{abstract}

\section{INTRODUCTION}

Pneumoconiosis is one of the main occupational diseases for Hong Kong construction workers [1]. Although medical technologies are well developed, there is no effective treatment for health and safety patients. Construction workers have the highest possibility to be inflected for health and safety than other industrial workers. According to the data provided by the Labour Department in Hong Kong [1], the number of inflected health and safety cases has persisted to decrease for 5 years. However, among about 256 cases of occupational disease confirmed in 2005, pneumoconiosis ranked second of about 68 cases received. From the statistics of the Pneumoconiosis Compensation Fund Board, at the same year, about $\$ 29$ million was payable to the injured employees in minor cases and in cases involving sick leave exceeding three days.

Compared with other personal protective equipment (PPE), like safety helmets or safety shoes, awareness of wearing respirators is low. Workers who did not wear safety helmets or safety shoes can receive immediate accidents, but the respirators are for health hazards. Doubtlessly that using personal respiratory protective equipment (PRPE) under hot, humid, confined and poor ventilated area is uncomfortable for workers. The workers would think that wearing the PPE lets them inconvenience and discomfort during the operations. Health and safety has not been immediately aware, hence, it is more dangerous for frontline workers.

Address correspondence to this author at the: Griffith School of Engineering, Griffith University, PMB 50 Gold Coast Mail Centre, QLD 9726, Australia; Tel: (61) 07-5552-9278; Fax: (61) 07-5552-8065;

E-mail: v.tam@griffith.edu.au
The Hong Kong government issued Chapter 360 Pneumoconiosis (Compensation) Ordinance to compensate for those suffered from health and safety as being a craftsman on sites [2]. Green developed a reputation risk management program to show that prevention is better than cure [3]. It is always better to prevent bad fortune from happening, then to cure it after it had been happened. Preventive measures for health improvement in the construction industry could be achieved only if concerns raised upon workers' inappropriate practice on construction sites. Regardless of the statutory requirement imposing in construction sites, most construction workers are unwilling to use PPE such as hardhat, protective gloves, goggles, respirator, ear plugs and safety belts. The PPE is used to protect workers against ill health and injury. Thus, for a long term measure, education of health awareness can help preventing problems on health and safety related risks. Before achieving the long-term measures, wearing mask seems to be the most effective and essential way of prevention.

Therefore, this paper aims:

1) To examine perceptions on health and safety hazards;

2) To investigate adverse outcomes including health and safety from hazards;

3) To analyse awareness and attitude to use on site prevention equipments;

4) To study the existing legal implication in wearing PRPE at site work; and

5) To provide recommendations in effectively reducing health and safety disease hazards on site. 


\section{HEALTH AND SAFETY HAZARDS}

Hazards exist at every job site. This must be controlled if job is going to be completed in a right way $[4,5]$. Hazards exist in many forms. A hazard has the potential to cause harm and risk as a function of the likelihood of the risk event and its consequence should it occurs. A hazardous condition exists when somebody is in danger of being injured or is exposed to a hazardous environment that could affect their health. Health and safety hazards may or may not produce immediate symptoms, but it has been gaining wider recognition in construction. Among these dangers are heat, radiation, noise, dust, shocks and vibrations, and toxic chemical [6-8]. Therefore, the hazard is a condition or changing set of circumstances that presents a potential for injury, illness or property damages [7-9] .

Table 1. Types of Health and Safety Diseases Dependence of the Types of Health and Safety Diseases on the Material Inhaled [1]

\begin{tabular}{|c|c|}
\hline Disease & Material inhaled \\
\hline \hline Silicosis & Free silica dust \\
\hline Berylliosis & Beryllium particles \\
\hline Byssinosis & Cotton dust \\
\hline Metal fume fever & $\begin{array}{c}\text { Particulates of zinc, magnesium, } \\
\text { copper and oxides }\end{array}$ \\
\hline Siderosis & Iron oxide \\
\hline Kaolinosis & Kaolin \\
\hline Mica pneumoconiosis & Mica dust \\
\hline Bauxite pneumoconiosis & Aluminium oxide fumes \\
\hline
\end{tabular}

Based on the Chapter 360 Pneumoconiosis (Compensation) Ordinance [2], meaning of pneumoconiosis is: i) fibrosis of lungs due to dust of free silica or dust containing free silica, whether or not such disease is accompanied by tuberculosis of the lungs, or any other disease of pulmonary or respiratory organs caused by exposure to such dust; or ii) fibrosis of lungs due to dust of asbestos or dust containing asbestos, whether or not such disease is accompanied by tuberculosis of the lungs, or any other disease caused by exposure to such dust. Pneumoconiosis is a generic term describing a chronic occupational disease caused by the accumulation of dust motes in the lungs. Table 1 shows various types of health and safety diseases. The two most common diseases are silicosis and asbestosis (see Table 2). Over $90 \%$ of the cases received are working in the construction industry [1]. Table $\mathbf{3}$ and Table $\mathbf{4}$ summarise average age / degree of incapacity, and employment history of the health and safety cases received. Rather than from construction industry, the other cases were employed in ship building, repairing, demolition, and water transport, jade and gem polishing, enamel and ceramics making, and tombstone work. Table $\mathbf{5}$ notes the number of confirmed occupational disease in 2005 . It was found that tenosynovitis and silicosis are the two common health problems in the construction industry. Health and safety victims are usually prone to shortness of breath after expending physical energy and when the condition is serious, they experience difficulty in breathing, and suffer from coughing and declining lung function.

Table 2. Number of Health and Safety Cases Received [1]

\begin{tabular}{|c|c|}
\hline Year & Number of Cases Received for Silicosis \\
\hline \hline 2000 & 105 \\
\hline 2001 & 122 \\
\hline 2002 & 110 \\
\hline 2003 & 74 \\
\hline 2004 & 69 \\
\hline 2005 & 68 \\
\hline
\end{tabular}

Table 3. Average Age / Degree of Incapacity Analysis in 2004 [1]

\begin{tabular}{|c|c|c|c|}
\hline $\begin{array}{c}\text { Age } \\
\text { Group }\end{array}$ & $\begin{array}{c}\text { Number of } \\
\text { Cases }\end{array}$ & Average Age & $\begin{array}{c}\text { Average Degree of } \\
\text { Incapacity (in \%) }\end{array}$ \\
\hline \hline $40-49$ & 8 & 47 & 9 \\
\hline $50-59$ & 23 & 54 & 12 \\
\hline $60-69$ & 24 & 65 & 12 \\
\hline $70-79$ & 12 & 75 & 8 \\
\hline 80 or \\
above
\end{tabular}

Health and safety diseases are long-term health problems and no effective treatment once it has been contracted; therefore, prevention is particularly critical. Hazard control is any means of eliminating or reducing risks resulting from a hazard [9]. There is more on-site health and safety awareness than just telling workers to wear them. Inspections, audits, training, equipment, and preventive maintenance are methods to control hazards [10,11]. Risk assessment should not be carried out only once but it should be an exercise which should be done repeatedly at regular intervals. Formal review is better taken place on an annual basis.

PPE can be effective only if the equipment is selected based on its intended use, employees are trained in its proper use, and the equipment is properly tested, maintained, and worn. Civitello's study pointed out that exposure to toxic gases, fumes, dusts, and mists above acceptable concentration must be avoided [6]. When it is not feasible or possible to bring areas itself into compliance through the use of engineering and administrative controls, appropriate protective equipment or other protective measures are to be used to keep exposure of employees to air contaminants within the limits prescribed. Any equipment and technical measures used for this purpose must be reviewed for each particular use by a technically qualified person. In such circumstances, employees use all issued equipment at all times.

From construction site health and safety handbook for public work programme published by Environment, Trans- 
Table 4. Employment History of Health and Safety Cases Assessed in 2004 [1]

\begin{tabular}{|c|c|c|c|}
\hline \multirow{2}{*}{ Industry } & \multicolumn{2}{|c|}{ Length of Employment } & \multirow{2}{*}{ Total } \\
\cline { 2 - 4 } & Less than 10 Years & 10 Years or Above & 59 \\
\hline \hline Construction & 0 & 2 & 2 \\
\hline Jade / gemstone polishing & 0 & 2 & 2 \\
\hline Ship manufacturing & 0 & 1 & 1 \\
\hline Sailoring plastic product manufac- \\
turing
\end{tabular}

port and Works Bureau [12], it is necessary to wear suitable respirators for protection when: i) sanding and rubbing down wood, filling materials and old paint; ii) spray painting; iii) steam cleaning; iv) cleaning cooling coils and filters with high pressure jets; v) all processes involving asbestos or asbestos based products, lead, and harmful or toxic chemicals in open vessels; vi) all processes that may give out silica dust or mercury vapour; vii) all work in a confined space; viii) atmosphere contains a nuisance, harmful or toxic dusts or gases; and ix) for rescue purposes. PRPE is a device that protect workers from inhaling harmful substances. These substances can be in the form of airborne vapors, gases, dust, fogs, fumes, mists, smokes, or sprays. Some PRPE also ensure that workers do not breathe air that contains dangerously low levels of oxygen. There are two major types of PRPE: i) air-purifying respirators, which remove contaminants from the air; and ii) atmosphere-supplying respirators, which provide clean air from an uncontaminated source. PRPE protect workers against insufficient oxygen environments, harmful dusts, fogs, smokes, mists, gases, vapors, and sprays. These hazards may cause cancer, lung impairment, other diseases, or death.

\section{AWARENESS AND RESPONSIBILITY ON USING PERSONAL RESPIRATORY PROTECTIVE EQUIP- MENT}

Many workers are unaware of potential hazards present in their working environment, which let them more vulnerable to injury. The workers complained that using PPE can slow down their efficiency, which also brings them uncomfortable feeling $[13,14]$. Industrial accidents and occupational health and safety should be a major concern for organizations and society as a whole and those human factors play a major role in the causation and prevention of such accidents [15]. Discerning shareholders, clients and employees are increasingly putting pressures on corporations to act in a socially responsible way. This includes managing health and safety welfare of their employees [16].

According to Guidance Notes on Protection of Quarry and Construction Workers from Silicosis [17], employer is responsible to ensure that he / she protects his / her employees from health hazards at work and should take all necessary practicable measures. Employee is responsible to make proper use of equipment including personal protection de- vices such as dust masks when these are necessary and provided for safeguarding health. In general, employee is responsible to wear and to use appropriate PPE in operations where there is exposure to hazardous conditions or where need is indicated to reduce hazards. Company is endeavour to anticipate all such needs and issue appropriate PPE, but it remains the employee's responsibility to use all such issued equipment, and to advise company management had not been issued [6]. All employees on a worksite should understand their own health and safety responsibilities $[18,19]$. Kennedy's study opined that never assume that a new worker, young or old, experienced or inexperienced, knows how to do the job in a safe way [4]. Manager should take advantage of any work-related health and safety training that is available, for example, seminars, videos, manufacturer's instructions, journals and books. There is nothing more important than on-site health and safety and health and safety of crews. Responsibility for managing a crew's health and safety is importance. Supervisor at any worksite is representing their companies, a spokesperson for a company's health and safety management program. He / she must recognize and reacts to unsafe behaviour or conditions on the spot. Physical hazards must be corrected, isolated, or barricaded as soon as possible, and to walk away from an unsafe act without responding to condone the act and to encourage it to be repeated in the future. The supervisors should be quick to praise safe behaviour, something that often get lost in the shuffle of day-to-day worksite activities [18,20].

Top management employees cannot delegate responsibilities in the area of the prevention programs. Employers, company presidents and plant managers must be willing to accept the responsibilities for occupational health and safety as an integral part of their jobs. They must establish health and safety policies, stimulate awareness of their health and safety, and show their own interests if others are to cooperate in making working conditions safe and healthful. Although attitude toward health and safety regulations and enforcement is negative, workers admit that health and safety regulations can protect them from accidents. However, the workers do not have a general picture on the health and safety regulations, in which they consider that main contractors are responsible for site health and safety, not the workers by law $[13,21,22]$. Chan and Tam's study suggested that government's attitude towards construction health and safety was 
an enforcement approach. This means that health and safety legislation was enacted to enforce contractors to follow it. However, this has created a culture for contractors in Hong Kong to "avoid" convictions [23]. Ong's study noted that it is important to consider management attitude and cost involved to implement preventive measures [24]. Cost and benefit are the main concerns for factory or plant managers. It is difficult to convince a manager of a construction company to purchase expensive protective equipment as a control measure against harmful dusts unless the manager considers that worker's health and safety is relevant to their benefit. However, management attitude towards health and safety and health controls of workers is extremely important. Worker's attitude towards health and safety performance and worker's perception of control over their own health and safety on the job were found significantly related to their perception of management's attitude towards health and safety practice and foreman's health and safety enforcement.

Table 5. Number of Confirmed Occupational Health and Safety Disease in 2005 [1]

\begin{tabular}{|c|c|}
\hline Occupational Disease & Number \\
\hline \hline Tenosynovitis of hand or forearm & 75 \\
\hline Silicosis & 68 \\
\hline Occupational deafness & 60 \\
\hline Tuberculosis & 30 \\
\hline Occupational dermatitis & 10 \\
\hline Streptococcus suis infection & 6 \\
\hline Gas poisoning & 4 \\
\hline Asbestos-related diseases & 2 \\
\hline Compressed air illness & 1 \\
\hline Total & 256 \\
\hline
\end{tabular}

\section{RESEARCH METHODOLOGY}

To examine awareness, attitude and practice in using PRPE for construction projects, a questionnaire survey was conducted. Management teams and frontline workers were the survey targets which aim to show possible similarities and differences between management level considerations and on site practice. The survey was sent to 250 parties including various management teams and frontline workers working in demolition projects with company sizes within 100 employees. 203 had been received with the response rate of about $81.2 \%$.

After received the questionnaire responses, individual structured interviews were arranged with eight interviewees, selected from the questionnaire respondents and different management levels: three from top management level, three from middle management level and two from frontline workers. The interviews were intended for gathering further comments; elaboration and interpretation on the results obtained from the questionnaire.

\section{RESULTS AND DISCUSSIONS}

\section{Background of the Respondents}

Table 6 shows the summary of the respondents' background. As construction industry is a male-dominant industry, it was found that about $87.2 \%$ of the respondents are male. About $66.2 \%$ of the respondents are between 20 and 39 years old. Over $77 \%$ of the management team respondents received at least diploma education; while majority of the frontline worker respondents received primary and secondary school education.

For the respondents' position level, about $19.4 \%$ of the management team respondents are site supervisors; about $16.4 \%$ are site officers; and about $13.4 \%$ are assistant engineers. The other management team respondents are project managers, assistant project managers, site agents, engineers, health and safety officers, health and safety supervisors, and project co-ordinators. Furthermore, about $21.8 \%$ of the frontline worker respondents are handymen. The other frontline worker respondents are bamboo scaffolders, bar benders and fixers, carpenters, concreters, excavators, levellers, masons, painters, decorators, plasterers, plumbers, tillers, and welders.

Majority of the respondents have less than five-year working experience and six- to ten-year experience of about $33.2 \%$ and $29.3 \%$. In the Hong Kong working environment, it is very competitive, in which their working period is normally quite long. From the survey, majority of the respondents are working for six days per week of about $73.3 \%$ and nine hours per day of about $48.7 \%$. From the interview discussions, one of the interviewees noted that members of a management team normally leave office after their supervisor(s) left.

With respect to the respondents' regular body check routine, about $74.6 \%$ of the respondents did not perform the regular body checking. An interviewee noted that he normally does the checking only because of his personal health problems.

\section{Understanding Respiratory Diseases}

Table 7 summarises the survey results on the understanding of respiratory diseases. About $84.9 \%$ and $72.1 \%$ of the respondents did not sustain a respiratory disease, injury or impairment themselves or their family members or friends respectively while employed. Majority of the respondents heard about pneumoconiosis and with certain extent of the understanding from various channels. From the interview discussions, the interviewees noted that most employees are aware of the seriousness of various respiratory diseases, and their knowledge mostly gained from various promotion materials. The most common channels receiving the information for health and safety are training courses and television programs of about $33.2 \%$ and $25 \%$ respectively. Therefore, the interviewees suggested the government and related organizations should provide more training courses to construction practitioners in enhancing their awareness. 
Table 6. Survey Results on Respondents' Background

\begin{tabular}{|c|c|c|c|}
\hline & Management Team & Frontline Worker & Total \\
\hline & \multicolumn{3}{|c|}{$($ In \%) } \\
\hline Male & 92.5 & 83.6 & 87.2 \\
\hline Female & 7.5 & 16.4 & 12.8 \\
\hline \multicolumn{4}{|c|}{ Age group } \\
\hline Below 20 & 0.0 & 0.9 & 0.5 \\
\hline $20-29$ & 43.3 & 24.6 & 32.1 \\
\hline $30-39$ & 38.8 & 30.9 & 34.1 \\
\hline Uneducated & 0.0 & 3.6 & 2.2 \\
\hline Primary school & 1.5 & 43.6 & 26.6 \\
\hline Secondary school & 20.9 & 48.2 & 37.2 \\
\hline $\begin{array}{l}\text { Diploma / higher diploma / associ- } \\
\text { ated degree }\end{array}$ & 41.8 & 4.6 & 19.6 \\
\hline Degree or above & 35.8 & 0.0 & 14.5 \\
\hline \multicolumn{4}{|c|}{ Position } \\
\hline Safety officer & 7.5 & 0.0 & 3.0 \\
\hline Health and safety supervisor & 6.0 & 0.0 & 2.4 \\
\hline Project co-ordinator & 10.5 & 0.0 & 4.2 \\
\hline Site supervisor & 19.4 & 0.0 & 7.8 \\
\hline Site officer & 16.4 & 0.0 & 6.6 \\
\hline Bamboo scaffolder & 0.0 & 3.6 & 2.2 \\
\hline Bar bender and fixer & 0.0 & 0.9 & 0.5 \\
\hline Carpenter & 0.0 & 5.5 & 3.3 \\
\hline Concreter & 0.0 & 0.9 & 0.5 \\
\hline Excavator & 0.0 & 9.1 & 5.4 \\
\hline Site surveyor & 0.0 & 6.4 & 3.8 \\
\hline Mason & 0.0 & 0.9 & 0.5 \\
\hline Painter and decorator & 0.0 & 9.1 & 5.4 \\
\hline Plasterer & 0.0 & 3.6 & 2.2 \\
\hline
\end{tabular}


Table 6. contd....

\begin{tabular}{|c|c|c|c|}
\hline & Management Team & Frontline Worker & Total \\
\hline Tiler & 0.0 & 3.6 & 2.2 \\
\hline Welder & 0.0 & 2.7 & 1.6 \\
\hline Others & 1.5 & 24.6 & 15.2 \\
\hline \multicolumn{4}{|c|}{ Site experience } \\
\hline 5 years or below & 38.8 & 29.4 & 33.2 \\
\hline $6-10$ years & 23.9 & 33.0 & 29.3 \\
\hline $11-15$ years & 16.4 & 12.8 & 14.3 \\
\hline \multicolumn{4}{|c|}{ Average working day a week } \\
\hline Below 5 days / week & 1.5 & 1.8 & 1.7 \\
\hline 5 days / week & 4.5 & 7.3 & 6.2 \\
\hline 5.5 days / week & 32.8 & 2.8 & 14.9 \\
\hline 6 days / week & 59.7 & 82.6 & 73.3 \\
\hline 7 days / week & 1.5 & 5.5 & 3.9 \\
\hline \multicolumn{4}{|c|}{ Average working hour a day } \\
\hline 6 hours or below / day & 1.5 & 0.0 & 0.6 \\
\hline Yes, every year & 23.9 & 10.1 & 15.7 \\
\hline Yes, once every 2 years & 9.0 & 7.3 & 8.0 \\
\hline Yes, others & 1.5 & 0.0 & 0.6 \\
\hline
\end{tabular}

\section{Use of Respirators}

From the survey results on using respirators shown in Table 8, about $86.6 \%$ of the management team respondents and about $48.6 \%$ of the frontline worker respondents do not use respirators while working on construction sites. Responsibilities for managing a crew's health and safety are one of the most important elements on construction sites. During the interview discussions, one of the interviewees highlighted that to ensure health and safety behaviour and working environment on site, management team should take responsibilities to manage workers' health and safety by performing their health and safety behaviour. However, majority of the management team respondents did not perform well on using respirators on site, which is hard for frontline workers to follow directions for health and safety working environment.
According to construction site health and safety handbook for public work programme [12], employee is responsible to ensure that he/she protects his/her employees from health hazards at work and should take all necessary practicable measures. From the survey results, it was found that about $30.2 \%$ of the respondents did not receive training for the use of respirators while employed. From the interview discussions, the interviewees explained that based on the multi-layered subcontracting system in the construction industry, main contractors do not have responsibilities to train their subcontractors. However, employers of the frontline workers are the different layers of subcontractors, who did not provide training to the workers. Another interviewee argued that the government should control multi-layered subcontracting system and thus their employees can ensure their health and safety working environment. 
Table 7. Survey Results on Understanding Respiratory Diseases

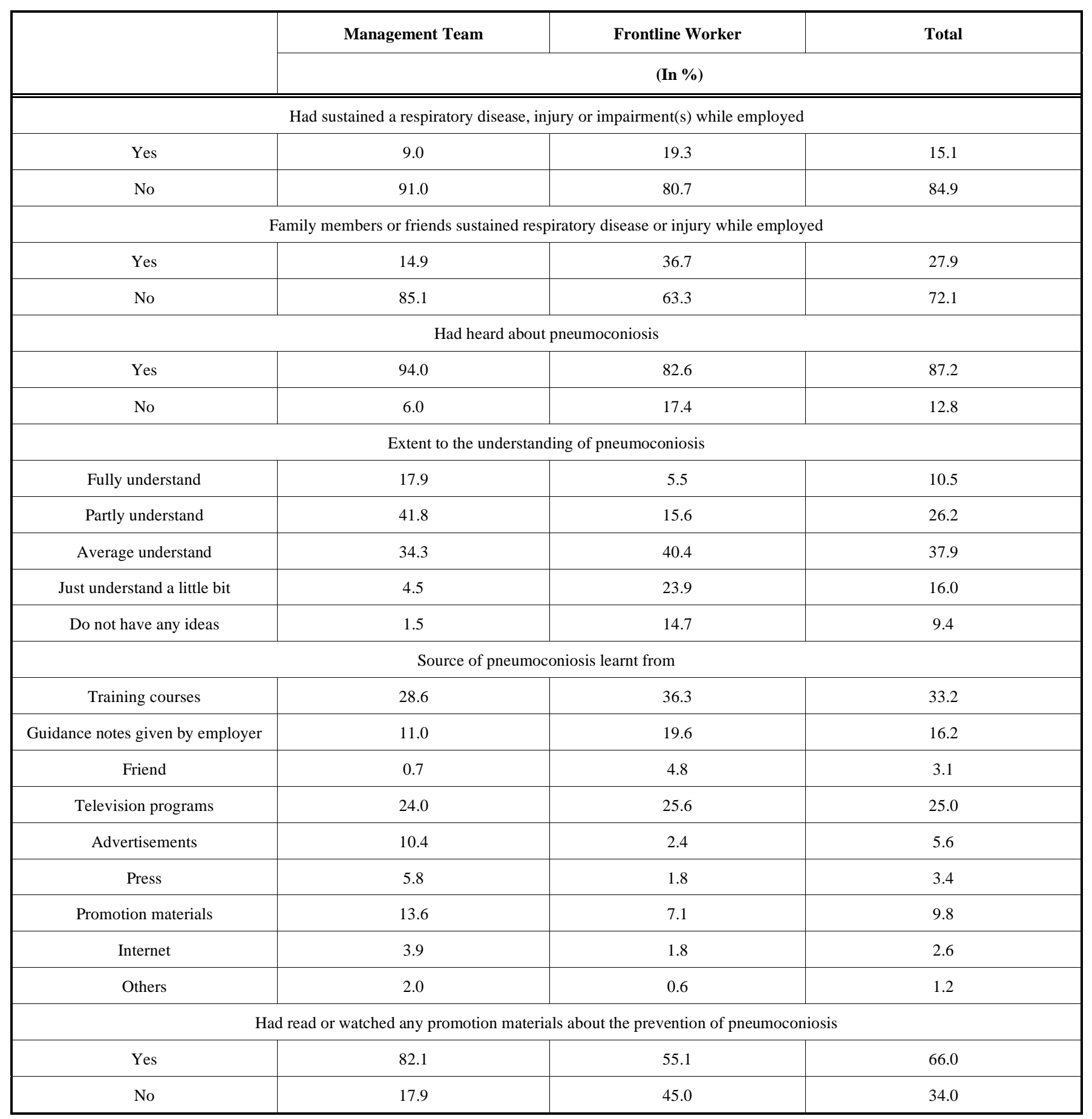

Health and safety promotion is an important element of prevention of health and safety hazards. Effective health and safety promotion on respiratory hazards can obtain positive effects. About $63.6 \%$ of the respondents understand the importance of using respirators on site from the promotion materials. It was also found that about $78.9 \%$ of the respondents are familiar with the risks of respirator fitting and about $80.8 \%$ of the respondents are familiar with respirator fitting. From the interview discussions, the interviewees argued that all employees should be familiar with the respirator fitting; it can directly affect their health. This also implicated that lack of training on the use of respirators is still occurred on construction sites.

From the survey results, although it is not all employees received training on the use of respirators and familiar with respirator fitting, about $94.5 \%$ of the respondents agreed with using respirators to avoid respiratory diseases or injury due to continuous working in dusty environment. This can b

highlighted that employees have awareness on the use of respirators on site to protect themselves. From the interview discussions, one of the interviewees highlighted that they can 
Table 8. Survey Results on Using Respirators

\begin{tabular}{|c|c|c|c|}
\hline & Management Team & Frontline Worker & Total \\
\hline Yes & 13.4 & 51.4 & 36.1 \\
\hline No & 86.6 & 48.6 & 64.0 \\
\hline Yes & 46.3 & 62.4 & 55.9 \\
\hline No & 53.7 & 37.6 & 44.1 \\
\hline \multicolumn{4}{|c|}{ Had been formally employed in a job where respiratory protection was used } \\
\hline Yes & 52.2 & 69.7 & 62.7 \\
\hline No & 47.8 & 30.3 & 37.3 \\
\hline \multicolumn{4}{|c|}{ Received training in general respirator donning or health and safety operations while employed } \\
\hline Yes & 68.7 & 70.6 & 69.8 \\
\hline No & 31.3 & 29.4 & 30.2 \\
\hline \multicolumn{4}{|c|}{ Had an idea of using respirators on sites because of promotion materials } \\
\hline Yes & 77.6 & 54.1 & 63.6 \\
\hline Quite unfamiliar & 7.5 & 22.9 & 16.7 \\
\hline Very unfamiliar & 1.5 & 6.4 & 4.4 \\
\hline \multicolumn{4}{|c|}{ Rate of familiarity with respirator fitting } \\
\hline Very familiar & 20.9 & 3.7 & 10.6 \\
\hline Quite familiar & 35.8 & 20.2 & 26.5 \\
\hline Average familiar & 40.3 & 45.9 & 43.6 \\
\hline Quite unfamiliar & 1.5 & 22.0 & 13.7 \\
\hline Very unfamiliar & 1.5 & 8.3 & 5.5 \\
\hline \multicolumn{4}{|c|}{ Thought of using respirators at sites being important } \\
\hline Yes & 89.6 & 58.6 & 71.1 \\
\hline No & 10.5 & 41.4 & 28.9 \\
\hline \multicolumn{4}{|c|}{ Agreed with using respirators to avoid respiratory disease or injury due to continuous working in dusty environment } \\
\hline Yes & 98.5 & 91.7 & 94.5 \\
\hline No & 1.5 & 8.3 & 5.5 \\
\hline
\end{tabular}


Table 8. contd....

\begin{tabular}{|c|c|c|c|}
\hline & Management Team & Frontline Worker & Total \\
\hline & \multicolumn{3}{|c|}{$(\operatorname{In} \%)$} \\
\hline \multicolumn{4}{|c|}{ Agreed with employer to be necessary to provide respirators for all workmen at sites } \\
\hline Yes & 92.5 & 86.2 & 88.8 \\
\hline No & 7.5 & 13.8 & 11.2 \\
\hline \multicolumn{4}{|c|}{ Used respirators provided by construction company or employer } \\
\hline No & 11.9 & 14.7 & 13.6 \\
\hline \multicolumn{4}{|c|}{ Agreed with lack of using respirators at sites to be punished } \\
\hline Yes & 64.2 & 49.5 & 55.5 \\
\hline No & 35.8 & 50.5 & 44.6 \\
\hline No & 41.8 & 64.2 & 55.2 \\
\hline \multicolumn{4}{|c|}{ Agreed with using respirators at sites to be legislated in occupational health and safety regulations } \\
\hline Yes & 73.1 & 37.6 & 52.0 \\
\hline No & 26.9 & 62.4 & 48.0 \\
\hline
\end{tabular}

understand the importance of using PPE, however, it will lower their efficiency and productivity. Therefore, not all employees are using respirators on site based on tight construction period.

\section{Health and Safety Responsibilities}

From the survey results shown in Table 9, about $73.6 \%$ of the respondents agreed poor level of air contaminants on sites. From the interview discussions, the interviewees are glad to know that their management team staff understands their working environment. Furthermore, about $93.4 \%$ of the respondents agreed the necessity for workmen to use respirators at sites to protect themselves. One of the interviewees explained that most projects are carried out along the roads; air contaminant level is unacceptable, especially on windy day. It is necessary to protect themselves by using respirators.

About $90.9 \%, 94.1 \%$ and $93.3 \%$ of the respondents agreed that workmen health and safety responsibilities are from workmen themselves, supervisors and site management teams respectively. From the interview discussions, an interviewee noted that minimizing risks of suffering from health and safety related diseases should be the own responsibilities for workmen to protect themselves. Another interviewee also explained that supervisors and site management teams can only alert workmen using respirators in reducing the chances of health and safety related diseases; however, the main driving force in using respirators is still come from workmen. Another interviewee suggested that responsibilities towards health and safety should be shared among employers, management teams and workers to achieve the optimal results and prevention.

Although majority employees understand the seriousness of health and safety, from the survey results, about $81.3 \%$ of the respondents agreed that permitted work can be continuous even if workmen do not use respirators. This reflected lack of awareness of workmen on on-site health and safety. One of the interviewees suggested that the government should implement regulations and ordinances to protect employees' health and safety at early development stage.

\section{Health and Safety Legislations}

Regarding to the responsibilities if prosecuted due to the lack of using respirators at sites, about $87.5 \%$ and $90 \%$ of the respondents agreed that responsibilities should be from employers and workmen respectively (see Table 10). As discussed in the last section, an interviewee suggested that share responsibilities between employer and workmen can enhance health and safety awareness for both parties.

Although the respondents have different ideas for health and safety responsibilities, about $74.3 \%$ of the respondents agreed that it has comparatively lower awareness of using respirators than other PPE, including safety helmets and safety shoes. As discussed earlier, an interviewee explained that wear respirators is very discomfortable, which can also lower their efficiency and productivity.

Only half of the respondents agreed that Chapter 360 Pneumoconiosis (Compensation) Ordinance is fully covered for all related workers from the survey. From the interview discussions, an interviewee argued that the ordinance can only penalty employers lack of care to their employees.

Another interviewee explained that the ordinance is very clear in the health and safety responsibilities. Therefore, about $86.9 \%$ of the respondents agreed that ordinance for compulsory use of respirators can minimize risks of suffering from health and safety hazards.

About $86 \%$ of the respondents agreed that involving awareness of health and safety in green card testing system 
Table 9. Survey Results on Health and Safety Responsibilities

\begin{tabular}{|c|c|c|c|}
\hline & Management Team & Frontline Worker & Total \\
\hline & \multicolumn{3}{|c|}{$(\operatorname{In} \%)$} \\
\hline \multicolumn{4}{|c|}{ High level of air contaminants on sites } \\
\hline Strongly agree & 23.2 & 27.8 & 25.9 \\
\hline Agree & 54.1 & 43.3 & 47.7 \\
\hline Strongly disagree & 0.0 & 15.7 & 9.4 \\
\hline No comment & 10.2 & 0.0 & 4.1 \\
\hline \multicolumn{4}{|c|}{ Necessity for workmen to use respirators at sites to protect themselves } \\
\hline Strongly agree & 35.9 & 43.1 & 40.2 \\
\hline Strongly disagree & 0.0 & 5.5 & 3.3 \\
\hline No comment & 2.2 & 1.5 & 1.8 \\
\hline \multicolumn{4}{|c|}{ Workman's own responsibility to protect themselves } \\
\hline Strongly agree & 42.5 & 46.8 & 45.1 \\
\hline Agree & 48.7 & 43.9 & 45.8 \\
\hline Disagree & 6.5 & 6.8 & 6.7 \\
\hline Strongly disagree & 0.8 & 1.1 & 1.0 \\
\hline No comment & 1.5 & 1.4 & 1.4 \\
\hline No comment & 2.8 & 0.3 & 1.3 \\
\hline \multicolumn{4}{|c|}{ Site management team's responsibility to alert the workmen to use respirators } \\
\hline Strongly agree & 34.5 & 41.4 & 38.7 \\
\hline Agree & 54.0 & 55.1 & 54.6 \\
\hline Disagree & 11.5 & 2.3 & 6.0 \\
\hline Strongly disagree & 0.0 & 0.9 & 0.5 \\
\hline No comment & 0.0 & 0.3 & 0.2 \\
\hline \multicolumn{4}{|c|}{ Permitted work when workmen do not use respirators } \\
\hline Strongly agree & 29.6 & 44.4 & 38.4 \\
\hline Agree & 38.4 & 46.0 & 42.9 \\
\hline Disagree & 21.8 & 4.4 & 11.4 \\
\hline Strongly disagree & 2.2 & 4.9 & 3.8 \\
\hline No comment & 8.0 & 0.3 & 3.4 \\
\hline
\end{tabular}

can significantly help improving health and safety awareness for the workers. From the interview discussions, one of the interviewees suggested involving basic knowledge of health and safety hazards and its health and safety protective methods in the green card testing system to ensure every on-site worker have enough knowledge on health and safety. 
Table 10. Survey Results on Health and Safety Legislations

\begin{tabular}{|c|c|c|c|}
\hline & \multicolumn{2}{|c|}{ Management Team } & Total \\
\hline \multicolumn{4}{|c|}{ Employer's responsibility if prosecuted due to the lack of using respirators at sites when using respirators at sites is legislated in regulation } \\
\hline Strongly agree & 21.7 & 32.5 & 28.1 \\
\hline Agree & 58.0 & 60.4 & 59.4 \\
\hline No comment & 4.4 & 0.3 & 2.0 \\
\hline \multicolumn{4}{|c|}{ Workman's responsibility if prosecuted due to the lack of using respirators at sites when using respirators at sites is legislated in regulation } \\
\hline Strongly agree & 34.7 & 31.3 & 32.7 \\
\hline Agree & 55.7 & 58.4 & 57.3 \\
\hline No comment & 4.4 & 0.3 & 2.0 \\
\hline \multicolumn{4}{|c|}{ Comparatively low awareness of using respirators than other personal protective equipment } \\
\hline Strongly agree & 13.9 & 15.3 & 14.7 \\
\hline Agree & 57.9 & 60.8 & 59.6 \\
\hline Disagree & 23.8 & 19.1 & 21.0 \\
\hline Strongly disagree & 3.0 & 3.4 & 3.2 \\
\hline No comment & 1.5 & 1.5 & 1.5 \\
\hline \multicolumn{4}{|c|}{ Chapter 360 Pneumoconiosis (Compensation) Ordinance is fully covered for all related workers } \\
\hline Strongly agree & 9.4 & 10.4 & 10.0 \\
\hline \multicolumn{4}{|c|}{ Ordinance for compulsory use of respirators to minimize risks of suffering from pneumoconiosis is essential } \\
\hline Strongly agree & 20.9 & 16.7 & 18.4 \\
\hline Agree & 68.1 & 68.7 & 68.5 \\
\hline Disagree & 5.2 & 4.2 & 4.6 \\
\hline Strongly disagree & 1.5 & 6.9 & 4.7 \\
\hline No comment & 4.5 & 3.5 & 3.9 \\
\hline \multicolumn{4}{|c|}{ Involve awareness of health and safety in green card testing system } \\
\hline Strongly agree & 22.4 & 17.9 & 19.7 \\
\hline Agree & 65.9 & 66.6 & 66.3 \\
\hline Disagree & 5.2 & 4.2 & 4.6 \\
\hline Strongly disagree & 0.0 & 7.9 & 4.7 \\
\hline No comment & 6.5 & 3.5 & 4.7 \\
\hline
\end{tabular}

\section{RECOMMENDATIONS}

Human factors play a major role in the causation and prevention of accidents and unsafe behaviour. To deal with the problems of low health and safety performance, following recommendations are raised.

\section{Legislation}

According to the Construction Sites (Health and safety) Regulations [2], all persons entering and remaining on a construction site must have worn safety helmet. Injured with falling objects and bumping hazards was greatly improved. With the success in using safety hamlet, it is suggested that 
using respirators at sites should be legislated in Occupational Health and Safety Regulation. It is no doubt that unsafe behaviour of worker must be enforced to attend health and safety training courses before returning to site for work. The health and safety awareness among frontline workers is low. Many people may have an idea that only concreter and excavator, have a high potential to suffer from health and safety hazards. According to Hong Kong Economic Times [25], there was a welder suffered from Bauxite pneumoconiosis due to the inhalation of aluminium oxide fumes over a long period.

Legislation is one of the methods to change people behaviour, but in a compelling way. From the survey result, it was indicated that health and safety attitude of workers is positive but behaves negatively. This "right attitude" with "inappropriate behaviour" can be modified by changing the behaviour. Therefore, to ensure health and safety among frontline workers, compulsory use of PRPE should be enforced. To certain extent, the reluctance to use PRPE under hot, humid and poor ventilated areas is understandable. However, worker's health and safety is valuable. The legislation is one of the most effective and immediate methods towards reducing the existing hazards.

\section{Health and Safety Management}

Management of an organization plays a momentous role in implementing controls for health and safety hazards and getting people in an organization to incorporate health and safety into their operations. Health and safety plan, committees, risk management and assessment and health and safety analyses, are essential of a health and safety management. Among these, details of site health and safety supervision would be highlighted in this study owing to a multi-layered subcontracting system is commonly occurred in Hong Kong construction; it is one of the immediate and effective methods to strongly improve worker unsafe behaviour.

Good site supervision is one of the requisite elements to uphold health and safe conditions as it can ensure the implementation and development of health and safety policy. Project manager, general work supervisor, health and safety officer, health and safety supervision and foreman, on-site management staff, are responsible to plan, direct, help, train, coach and guide workers to perform safely. By these, unsafe condition and behaviour can be examined. Instant remedy and improvement can also be given.

The education level and health and safety awareness of frontline workers are relatively low. Training and guidance from management is essential to modify worker's unsafe behaviour. In other words, health and safety leadership is particularly important at the level of site supervisor. As such, they play a key role in ensuring a effective health and safety management system operates. Working effectively in supervision requires good communication skill. Management team, especially senior mangers, can communicate about the significance of health and safety objectives powerfully if they lead by example. Workers, hence, perceive what their superiors regard as important and act accordingly. Additionally, regular health and safety tours showing example of good and bad performance should be arranged. It is easy for workers to practically understand health and safety issues.
Re-design, re-specification and revision of construction methods should also be considered to improve the on site health and safety performance. The use of PRPE should only be considered as an additional protection.

\section{Health and Safety Training}

Training is a fundamental unit of an effective health and safety program. By providing proper training, it can identify responsibilities between management team and frontline workers. The basic components of health and safety training should consist of a health and safety induction training and green card system.

It is required that every worker employed in a company should undertake the health and safety induction training. General and specific health and safety issues are consists of: i) employees' attitude on health and safety at work; ii) health and safety regulations and site health and safety rules; iii) safe working procedure and guidelines; iv) use of PPE; v) company health and safety policy; vi) general conditions of construction site; vii) special aspects of project and potential hazard; viii) emergency measures and first aids; and ix) accident reporting and claim procedures. Among these issues, it is recommended that it should be strongly pointed out the other consequence of health and safety which can affect long-term health and safety effects. The training program should be designed to ensure all employees

understand and are aware of health and safety hazards to which they may be exposed and proper methods to avoid it. Therefore, it is better to explain in details how the invisible respirable particles penetrate the smallest airways in the lung.

The green card system is a mandatory basic health and safety training course for all employees. However, usually, it is a one-day course. It does not mention much about respiratory hazards, corresponding protective equipment and other issues. Thus, there should be one compulsory or an individual section for the awareness of health and safety in the existing green card system.

\section{CONCLUSION}

This paper investigated subjects on how to improve and helps craftsmen, frontline workers, on minimizing health and safety risks. In addition, awareness, attitude, behaviours and current practice of the management team and frontline worker were examined. Questionnaire survey and structured interviews were conducted. From the survey results, it was found that awareness and understanding of the health and safety hazards is insufficient. Moreover, workers are not familiar with the risks of respirator fitting. Health and safety awareness can influence health and safety attitude and behaviour. The lack of training on health and safety issues causes low awareness of health and safety which would make worker more vulnerable to illness, and thus low health and safety performance. Implement sufficient mitigation measures should be the first step to improve health and safety performance in the construction industry. Recommendations to improve health and safety awareness and understanding of respiratory diseases were also given in this study. 


\section{REFERENCES}

[1] Labour Department. Safety environment. 2007 [cited 2007 May, 8]; Available from: http://www.info.gov.hk/ld.

[2] Legislative Council. Legislations. 2007 [cited; Available from: http://www.legislation.gov.hk.

[3] S.P. Green, Reputation risk management. Pitman Publishing, 1992.

[4] G. Kennedy, Construction foreman's safety handbook. Albany: Delmar, 1997.

[5] S. Clarke, The relationship between safety climate and safety performance: a meta-analytic review. Journal of Occupational Health Psychology 11 (4) (2006) 315-327.

[6] A.J. Civitello, Construction safety and loss control program manual. Armonk, New York, M.E. Sharpe, 1998

[7] D. Zohar, Safety climate in industrial organizations: theoretical and applied implications. Journal of Applied Psychology 65 (1) (1980) 96-102.

[8] D. Zohar, Safety climate and beyond: a multi-level multi-climate framework. Safety Science In Press (2007).

[9] D.S. Barrie, B.C. Paulson, Professional construction management: including construction management, design-construct, and general contracting. New York: McGraw-Hill, 1992.

[10] W.H. Fung, C.M. Tam, Effectiveness of safety management strategies on safety performance in Hong Kong. Department of Building and Construction, City University of Hong Kong, China, 1994.

[11] D. Diaz-Cabrera, E. Hernandez-Fernaud, R. Isla-Diaz, An evaluation of a new instrument to measure organisational safety culture values and practices. Accident Analysis and Prevention 39 (6) (2007) 1202-1211.

[12] Environment Transport and Works Bureau. Construction site safety handbook for public work programme 2007 [cited 2007 May, 2]; Available from: http://www.etwb.gov.hk/.

[13] O.P. Tse, A study on the attitude of workers to construction site safety in Hong Kong. Department of Building and Real Estate, City Polytechnic of Hong Kong, 1994.
[14] G. Grote, Diagnosis of safety culture: a replication and extension towards assessing "safe" organizational change processes. Safety Science In Press (2007)

[15] N. Holmes, H. Lingard, Understandings of occupational health and safety risk control in small business construction firms: barriers to implementing technological controls. New York: McGraw-Hill, 2001.

[16] H. Lingard, S. Rowlinson, Occupational health and safety in construction project management. London: New York: Spon Press, 2005.

[17] Labour Department, Guideance notes on protection of quarry and construction workers and silicosis. Occupational Safety and Health Branch, Labour Department, Hong Kong Government, 2000.

[18] D. Heberle, Construction safety manual. New York: McGraw-Hill, 1998.

[19] K. Haukelid, Theories of (safety) culture revisited - an anthropological approach. Safety Science In Press (2007).

[20] S.E. Johnson, The predictive validity of safety climate. Journal of Safety Research In Press (2007).

[21] P. Swuste, WOS2006, regulatory issues, safety climate, culture, and management. Safety Science In Press (2007).

[22] B. Wilpert, Regulatory styles and their consequences for safety. Safety Science In Press (2007).

[23] P.C. Chan, C.M. Tam, Nourishing safety culture in the construction industry of Hong Kong. 2nd International Conference on the Implementation of Safety and Health on Construction Sites, Hawaii, United States of America, 1999 117-122.

[24] S.G. Ong, A study of the knowedge, attitude and practice of construction and quarry workers most at risk of silicosis. Department of Community Medicine, the University of Hong Kong, 1992.

[25] Hong Kong Economics Times. Information on pneumoconiosis 2007 [cited 2007 May, 12]; Available from: http://www.hket.com/hketonline/app.

(C) Tam and Fung; Licensee Bentham Open.

This is an open access article distributed under the terms of the Creative Commons Attribution License (http://creativecommons.org/licenses/by/2.5/), which permits unrestrictive use, distribution, and reproduction in any medium, provided the original work is properly cited. 